\title{
Leveraging Cloud-Based Mobile Education Platforms to Reach Individuals with Diabetes and Pre-Diabetes Efficiently
}

\author{
Keith J Zullig1*, Brian Krolczyk ${ }^{2}$, Ranjita Misra ${ }^{1}$ and Lee Smith ${ }^{3}$ \\ ${ }^{1}$ Department of Social and Behavioral Sciences, School of Public Health, West Virginia University, USA \\ ${ }^{2}$ Principal, RYP Global, USA \\ ${ }^{3}$ Monongalia County Health Department, Executive Director/County Health Officer, USA
}

Submission: April 05, 2018; Published: May 08, 2018

*Corresponding author: Keith J Zullig, Department of Social and Behavioral Sciences, School of Public Health, P.0. Box 9190, West Virginia University, Morgantown, West Virginia 26506-9190, USA, Email: kzullig@hsc.wvu.edu

\begin{abstract}
The United States has the 3rd highest number of people with diabetes (30 million) with an additional 84 million Americans having prediabetes. Diabetes is associated with multiple micro- and macro-vascular complications and leads to increased risk for blindness, stroke, heart attack, lower limb amputation, and kidney failure. West Virginia is unduly burdened by the disease, as approximately $12.5 \%$ of the population have diagnosed diabetes and an additional $35.9 \%$ of the population have prediabetes. Factors that contribute for high rates of diabetes and prediabetes in West Virginia include geography, lack of access to quality care, aging population, and transportation, in addition to poor lifestyle behaviors. New technologies afford the opportunity to deliver educational messages and provide support through digital communication capabilities. For example, technology that can deliver targeted text-messages to hundreds, if not thousands, of diabetic and pre-diabetic patients using mobile phone technology has the potential to address challenges experienced with the scalability of interventions. In addition, this technology has the ability to collectreal-time patient data, identified as a critical need in driving public health decision making.
\end{abstract}

Keywords: Mobile diabetes education; Health behavior; Text messaging; Patient satisfaction; Patient engagement; Access to care

\section{Introduction}

According to the United States (US) Centers for Disease Control and Prevention, approximately 30 million Americans have diabetes $(9.4 \%$ of the population) and an additional 84 million (33.9\% of the US population) have prediabetes [1]. Diabetes is a chronic and debilitating disease associated with multiple microand macro-vascular complications and leads to increased risk for blindness, stroke, heart attack, lower limb amputation, and kidney failure that leads to early mortality and lower quality of life if not managed or controlled. In West Virginia, the burden is even greater where approximately $12.5 \%$ of the age-adjusted population have diagnosed diabetes and additional $35.9 \%$ of the population have prediabetes [1]. Contributing factors for the high rates of diabetes and prediabetes in West Virginia include geography, lack of access to quality care, aging population, transportation, and poor lifestyle behaviors. Obesity, physical inactivity, and smoking are also high among West Virginians. The state was named the 2nd most obese state in 2017, with $35.6 \%$ of West Virginian adults considered obese [2]. However, symptoms of diabetes and prediabetes can be prevented by keeping blood glucose levels under control through proper nutrition, physical activity, and lifestyle choices.

Traditional methods of diabetes education and social support for behavior change include a wide range of delivery models and conventional support groups. Nonetheless, the degree to which these interventions and programs help patients create and sustain healthy behavior change varies due to limitations such as access, costs, and lack of follow up support. New technologies introduce opportunities to deliver education and social support through digital communication capabilities, such as textmessages. Thus, education and support can be delivered in "real-time" in the patients' home environment through their cell phone. Given the scope of this public health epidemic and the limited scope of traditional educational/intervention models to reach a large audience, new opportunities to create, deliver and evaluate scalable, evidence-based education is critically needed to impact successful behavior change. 
The effectiveness of traditional health education and support programming is limited by the requirements of attendance, transportation, time, and costs. Assuming the right education is provided along with adequate social support, there is still no guarantee of successful behavior change and health outcomes. The emergence of mobile technology as a method of improving effectiveness of education and training in the corporate environment is widespread and growing rapidly. For example, Thrive software technology (http://gothrive.io/) is one vendor providing a cloud-based learning communication platform service with sophisticated analytics. Thrive software is capable of sending a variety of multimedia content (narrative, inquiry, pictures, and video) which can be scheduled to meet the needs of health education program designers and participants. Additionally, participants can be surveyed in a variety of ways (sliding scales, multiple choice, and essay responses) allowing for real-time data collection and reporting. In summary, all of the science, creativity, and passion put into evidence-based interventions and programs can now be delivered digitally to a patient or family member's cell phone in small increments over time.

This presents a number of advantages. First, existing program content can now be "repackaged" in a manner that leverages the science of applied learning and motivation. A message prompting healthy eating can be precisely timed to arrive prior to a meal. Messages of encouragement can be sent to reinforce behavior changes such as meal planning and routine physical activity. More importantly, these potential advantages are gained without changes to existing standardized health education program content. Essentially, any evidence-based intervention or program can be "put on a platform" and "delivered" to a cell phone inbound text message box, one interesting short message at a time. For example, a participant can receive one, one-minute message a day, three days per week, for 12 months.

Second, data collection facilitates analytics that can address motivation, receptivity to change, additional resources needed, service utilization, even subjective well-being in real-time. Program administrators can access a dashboard, which provides real-time graphic interface with participant responses, historical participation rates, real-time data collection and analysis.

Third, the reliability of cloud-based systems are proven and capable of delivering multiple programs to an unlimited number of participants at once, therefore addressing questions of scalability, access to care, transportation, and geography that challenges states like West Virginia. Hence, the technology has the potential to empower providers in delivering individualized interventions and programs and facilitating real-time data collection for analysis. We encourage public and private healthcare providers, educators and communication professionals to explore the development, utilization and evaluation of mobile health education program for diabetic and pre-diabetic patients and other chronic diseases.

\section{Conclusion}

Evaluation projects can address two critical needs that affect public health and continued well-being. First, cloudbased programs have the potential to address challenges experienced with the scalability of interventions by eventually reaching hundreds, if not thousands, of diabetic and pre-diabetic patients using mobile phone technology. Second, this technology facilitates the need for collecting, and acting on, real-time patient data as highlighted by US Department Health and Human Service's "Public Health 3.0" 2016 report where they write "the importance of reliable, diverse, real-time data to drive public health decision making" (p.23) [3] is needed.

We believe that health care providers, local health departments, and patient education specialists will benefit from evaluation of cloud-based programs. They have intimate knowledge of their patients' needs and can help find ways to best integrate a mobile program with existing education efforts. We believe that aligning patient education/support efforts with broader public and private healthcare strategy is critical in sustaining program support, patient utilization and desired health outcomes.

\section{Conflict of Interest}

The authors declare potential economic interest in the commercialization of proprietary intellectual property.

\section{References}

1. National Diabetes Statistics Report (2017) Centers for Disease Control and Prevention, US Department of Health and Human Services. Atlanta, Georgia.

2. (2017) Trust for America's Health and the Robert Wood Johnson Foundation. Key Health Data about West Virginia, USA.

3. (2016) US Department of Health and Human Services, Office of the Assistant Secretary for Health. Public Health 3.0: a call to action to create a $21^{\text {st }}$ century public health infrastructure. 


\section{Current Research in Diabetes \& Obesity Journal}

This work is licensed under Creative Commons Attribution 4.0 Licens

DOI: 10.19080/CRDOJ.2018.07.555707
Your next submission with Juniper Publishers will reach you the below assets

- Quality Editorial service

- Swift Peer Review

- Reprints availability

- E-prints Service

- Manuscript Podcast for convenient understanding

- Global attainment for your research

- Manuscript accessibility in different formats

( Pdf, E-pub, Full Text, Audio)

- Unceasing customer service

Track the below URL for one-step submission https://juniperpublishers.com/online-submission.php 